\title{
Correction to: Postural responses to target jumps and background motion in a fast pointing task
}

\author{
Yajie Zhang $^{1,3}$. Eli Brenner ${ }^{1}$. Jacques Duysens ${ }^{2} \cdot$ Sabine Verschueren $^{3} \cdot$ Jeroen B. J. Smeets $^{1}$
}

Published online: 19 July 2018

○) Springer-Verlag GmbH Germany, part of Springer Nature 2018

\section{Correction to: \\ Experimental Brain Research (2018) 236:1573-1581 \\ https://doi.org/10.1007/s00221-018-5222-6}

The original publication of this paper contained an error. The background motion speeds were actually 20 and $60 \mathrm{~cm} / \mathrm{s}$ instead of the 2 and $6 \mathrm{~cm} / \mathrm{s}$ mentioned in the paper (also in figures). It does not affect any of the results, interpretation or conclusion.

The original article can be found online at https://doi.org/10.1007/ s00221-018-5222-6.

Yajie Zhang

y3.zhang@vu.nl

1 Department of Human Movement Sciences, Vrije Universiteit Amsterdam, Amsterdam Movement Sciences, Amsterdam, The Netherlands

2 Department of Kinesiology, FaBer, KU Leuven, Leuven, Belgium

3 Department of Rehabilitation Sciences, FaBer, KU Leuven, Leuven, Belgium 